\title{
GÊNERO, RAÇA, CLASSE: AS INTERNAS DA SEÇ̃̃o ESQUIROL PARA ALÉM DA LOUCURA
}

\author{
GENDER, RACE AND CLASS: THE INMATES OF THE ESQUUROL SECTION BEYOND MADNESS
}

\section{RESUMO}

Este trabalho analisa as práticas psiquiátricas e institucionais destinadas às mulheres loucas e pobres nas primeiras décadas da república brasileira, circunscreve o que era caracterizado como sendo a loucura feminina e reflete sobre como esta conceituação interage com outros discursos que definem o período. Para tanto, analisa 24 prontuários de pacientes transferidas do Hospital Nacional para a primeira instituição psiquiátrica exclusivamente feminina, a Colônia de Psicopatas do Engenho de Dentro. As informações destes documentos foram complementadas por outras, localizadas no Arquivo Nacional e no IPUB, como: memorandos, solicitações, relatórios e correspondências que narram aspectos cotidianos da colônia. A análise dos dados baseia-se no conceito de interseccionalidade, categoria que incorpora um dos eixos centrais da epistemologia feminista. Através dos resultados pode-se analisar a ação dos poderes institucionais interligados nos processos de tratamento dirigidos às mulheres internadas e o quanto eles refletem aspectos patriarcais, classistas e escravocratas da sociedade brasileira daquele momento.

Palavras-chave: Loucura. Feminino. Primeira República. Interseccionalidade.

\begin{abstract}
This paper analyzes the psychiatric and institutional practices aimed at crazy and poor women in the first decades of the Brazilian republic. It also circumscribes what was characterized as feminine madness and reflects on how this conceptualization interacts with other discourses that define the period. To this end, it analyzes 24 medical records of the patients transferred from the National Hospital to the first exclusively female psychiatric institution, the Colony of Engenho de Dentro Psychopaths. The information from these documents was complemented by others, located in the National Archives and IPUB, such as: memos, requests, reports and correspondence that narrate daily aspects of the colony. Data analysis is based on the concept of intersectionality, a category that incorporates one of the central axes of feminist epistemology. Through the results, it is possible to analyze the action of the interconnected institutional powers in the treatment processes aimed at
\end{abstract}

Renata P. F. de Valentim

UERJ. Email: renatapfvalentim@gmail.com

Mariah da S. Martins

UERJ. Email: mariahmartinsuerj@gmail.com

Letícia P. Martins

UERJ. Email: let_fac@hotmail.com

Tamiris R. M. de Freitas

Universidade do Estado do Rio de Janeiro (UERJ). Email: tamiris.freitas93@gmail.com 
hospitalized women and how much they reflect the patriarchal, classist, and slave aspects of Brazilian society at that time.

Keywords: Madness. Feminine. First Republic. Intersectionality.

\section{Introdução}

Este trabalho tem como questão central a descrição e a análise das práticas psiquiátricas e institucionais destinadas às mulheres pobres e loucas nas primeiras décadas da república brasileira. Pretende tanto circunscrever o que era caracterizado pela psiquiatria como sendo a loucura feminina; quanto refletir sobre como esta conceituação interage com outros discursos que definem este período histórico, tais como os discursos republicanos, patriarcais e raciais. Além disso, delinear quais as demandas, as exigências específicas de política social e moralidade, que estes discursos recém instaurados vão dirigir às instituições asilares que abrigavam estas mulheres.

Para tanto, analisa 24 prontuários das primeiras pacientes que foram transferidas do Hospital Nacional para aquela que seria a primeira instituição psiquiátrica exclusivamente feminina: a Colônia de Psicopatas do Engenho de Dentro. Fundada em 1911, no então longínquo subúrbio carioca do Engenho de Dentro, esta colônia foi construída para desafogar o excesso de pacientes abrigadas no Hospital Nacional de Alienados e, já em seus dois primeiros anos de funcionamento, recebe 334 mulheres, oriundas da seção Esquirol, uma divisão da seção feminina do hospital destinada às “indigentes” (Arquivo nacional, 1911-1918).

Os prontuários pesquisados são do ano de 1911 e foram localizados no Centro de Memória do Instituto Municipal Nise da Silveira, alguns mais completos que outros, mas que em geral se constituem por diversas fichas e guias: a ficha de internação da polícia; a do pavilhão de observação do Hospital Nacional; a ficha de internação no hospital; a da colônia; e diferentes guias que versam sobre as transferências, novas internações, altas e solicitações. À exceção de um prontuário, todos traziam a foto das pacientes. As informações contidas nestes primeiros documentos foram complementadas por outras, localizadas no Arquivo Nacional na seção "Saúde". São memorandos, solicitações, relatórios e correspondências que narram aspectos cotidianos da colônia, que foram trocados entre o diretor da colônia, Braule Pinto; Juliano Moreira, diretor do Hospital Nacional e diretor da Assistência MédicoLegal de Alienados; e o Ministério da Justiça e Negócios Interiores. Além disso, foram também pesquisadas as análises feitas por Henrique Roxo no Pavilhão de observações, que constam em documentos abrigados no Instituto de Psiquiatria da Universidade Federal do Rio de Janeiro (IPUB).

As primeiras colônias agrícolas inauguradas no Brasil em 1890 eram masculinas e localizavam-se na Ilha do Governador: a colônia de Conde de Mesquita e a de São Bento. Criadas "no mesmo clima republicano da fundação de um Estado" (Venâncio, 
2011: 38), elas funcionaram na prática como um instrumento para esvaziar o excesso de pacientes categorizados como "indigentes", internados no Hospital Nacional (Facchinetti, 2010). Os indigentes, como eram chamados aqueles que não podiam pagar pelo seu tratamento, deveriam trabalhar em atividades agrícolas e artesanais (no caso dos homens) ou avicultura e plantação de hortas (no caso das mulheres), caso fossem considerados aptos para tal. Possuíam como modelo aquelas instituições que antes já haviam sido destinadas ao tratamento de leprosos ou tuberculosos, instituições voltadas para o isolamento do doente e funcionalmente construídas para evitar a propagação de algum mal. Caso da colônia feminina, que se organiza em instalações antes destinadas ao tratamento de doentes beribéricos.

No caso da instituição psiquiátrica, a ideia de isolamento que se atualiza no discurso dos médicos alienistas baseia-se ainda em outra crença: a do "tratamento moral". Nele, o próprio isolamento é um critério terapêutico, que remete à pureza da vida rural e evita o contato do doente com os choques provocados pelo cotidiano da vida urbana, com os "males da civilização", considerados uma das principais causas das perturbações mentais. Para os alienistas, a experiência da internação em uma colônia traria ainda um bônus, que vinha na forma do resgate de algum sentimento de liberdade. A “ilusão da liberdade" (Amarante, 2016: 32).

Além do isolamento em meio rural, havia também a concepção de que o exercício do trabalho agrícola também pudesse desempenhar um papel terapêutico. Neste caso, um benefício de mão dupla que percebia a redenção do sujeito e de seu "mal" através do trabalho árduo com a terra, simbólico por sustentar uma soma de medidas e princípios "que pretendiam reeducar a mente, afastar os delírios e ilusões e chamar a consciência à realidade" (Amarante, 2016: 24). Mas benéfico também ao Estado pela possibilidade do interno se autossustentar, ideia defendida por alienistas como Braule Pinto justamente por conta deste seu caráter híbrido, misto de dispositivo terapêutico e de medida econômica (Arquivo Nacional, 1911-1918).

Pode-se dizer que a fundação das colônias, não apenas a do Engenho de Dentro, é um exemplo do esforço realizado no Brasil entre o final do século XIX e princípio do XX de modernizar sua produção científica e cultural. Foi um modo encontrado pelo poder republicano para reprimir a feição imperial e rural do país, ajustando-o aos recém-chegados moldes citadinos e burgueses. Novos padrões que virão no bojo de inúmeras outras transformações, tais como a urbanização dos espaços, o aparecimento das primeiras fábricas ou a chegada à cidade da massa de trabalhadores, imigrantes ou ex-escravizados que as iriam abastecer. Mudanças estruturais que exigiam novos instrumentos institucionais que as organizassem e impusessem suas normas.

O Rio de Janeiro, como capital do regime republicano, é o epicentro dessas mudanças sociais, econômicas e políticas. Para que elas pudessem se materializar, as primeiras décadas da república imprimem à cidade um redimensionamento das políticas de controle social, onde a "rigidez e abrangência eram produzidas pelo reconhecimento e legitimidade dos parâmetros burgueses definidores da ordem, do progresso, da modernidade e da civilização" (Engel, 2002: 323). No bojo destas 
medidas, estavam o inédito processo de medicalização da loucura e sua nova definição como doença mental, território cativo da psiquiatria, de seus saberes e práticas.

Como já foi falado, este artigo parte deste contexto de irrupção para circunscrever as formas da loucura feminina e pobre, seus diagnósticos e as práticas médicas a ela destinadas em relação às demais forças políticas que emergiam, pensando o como e o quanto a ideia de loucura feminina que surge está em interação com outros discursos do período. Para tanto, a pesquisa baseia-se no conceito de interseccionalidade (Crenshaw, 2002), onde uma conjunção de variáveis sociais, tais como raça, classe e gênero atuam na construção das identidades e faz toda diferença no entendimento de como diferentes grupos de mulheres vivenciam a discriminação. Segundo Crenshaw (2002: 173): "elementos diferenciais que podem criar problemas e vulnerabilidades exclusivos de subgrupos específicos de mulheres, ou que afetem desproporcionalmente apenas algumas mulheres".

Segundo Biroli e Miguel (2015) esta convergência nos possibilitaria justamente perceber o quanto o campo de estudos feministas não é homogêneo, como as desigualdades que se somam a de gênero atuam com diferentes pesos e importância na especificidade de cada grupo oprimido. E também o quanto o conjunto destas variáveis não significa uma sobreposição de padrões de dominação independentes, mas sim um entrelaçamento muito mais intricado, que se institucionaliza das mais variadas formas em uma "subordinação interseccional estrutural" (Crenshaw, 2002: 179)

Por um outro lado, segundo Hirata (2014), a categoria de interseccionalidade permitiria ainda incorporar um dos eixos centrais da epistemologia feminista ao questionar as pretensas neutralidade e universalidade científicas e relacionálas à visão de mundo daqueles que as criaram. No caso deste estudo, abrindo a possibilidade para a identificar no racismo científico das políticas eugenistas de manutenção da estrutura social e racial brasileira e nas práticas e dispositivos que se institucionalizam durante a primeira república, uma construção masculina, em sua esmagadora maioria branca, comprometida com ideais republicanos e com a inserção dos preceitos cientificistas na consecução desta nova fase da política nacional.

Investigar no processo de transferência das pacientes as demarcações discursivas que estão se instalando e definindo o conjunto de mulheres que deveria ser destinado a este novo espaço terapêutico, significa justamente circunscrever quais as formas de intervenção política e social abertas por (e para) a psiquiatria sobre aqueles comportamentos femininos considerados "desviantes" ou inadequados à tal ordem republicana. Como no estudo de Cunha (1989), espera-se assim compreender as forças que estavam em jogo na forma como a loucura feminina e pobre foi circunscrita e tratada, quais as "formas de enfrentamento, respaldadas nos saberes e na crença na ciência como fundamento do progresso" que foram dirigidas àquelas pobres e loucas que não se integravam ao padrão de um "imenso aglomerado humano laborioso e pacificado"(Cunha, 1989: 124).

Objeto destas demarcações discursivas hegemônicas, a palavra da mulher é comumente caracterizada como um discurso "vazio, fútil, insignificante (...) A não 
afirmação social da mulher reproduz-se na sua não-afirmação pela palavra. Tanto na vida quanto na arte elas ficam confinadas às construções masculinas” (Garcia, 1995: 26). Nesta perspectiva, pode-se dizer que as pacientes da seção Esquirol foram relegadas a muitos silêncios. Por um lado, o mesmo das demais mulheres do período, submetidas a uma legislação civil que as infantilizava e atribuía ao marido sua representação legal e a administração dos bens comuns, o direito de fixar o domicílio da família, de autorizar a profissão da mulher e dirigir a educação dos filhos (Brasil, 189o). Por outro, o mesmo escrutínio e exame das demais mulheres loucas, a mesma institucionalização construída para impossibilitar qualquer tentativa de singularização, ou ainda como dispositivo de isolamento e punição aquelas que tentaram e foram objeto do descrédito e da "recusa da sociedade em aceitar a autonomia feminina e encarar seu discurso como uma fala sem sentido, de louco" (Garcia, 1995: 28). O apagamento das histórias singulares e individuais, a patologização dos desejos, a normatização das condutas estão para todas.

Entretanto, há silêncios que decorrem de sua vulnerabilidade social e racial e se somam àqueles que já decorriam em função de seu gênero. Há o silêncio imposto pelo isolamento social e físico da colônia voltada para as "indigentes". Há também a presença da polícia médica como força interventora e órgão responsável pela internação da população pobre, pois se os ricos são isolados e vigiados em suas casas, aqueles que circulam livremente pelas ruas, os "perigosos em potencial" e aqueles que desafiam a moral pública, a caridade e a segurança serão objeto de controle da polícia médica desde o século XIX (Machado, Loureiro, Luz \& Muricy, 1978), além de serem também uma das razões da própria ordenação do espaço hospitalar (Amarante, 2016).

Partindo destas questões, que necessariamente engajam a pesquisa acadêmica em um campo social e político, a tentativa deste trabalho foi a de construir uma narrativa que, mesmo partindo dos prontuários e demais documentos, colocasse suas anotações sob rasura, retirando-as da neutralidade exigida por um documento científico, do qual se deve buscar o sentido original, único e verdadeiro. A ideia aqui é privilegiar nestes registros aspectos que recontem a história das intervenções médicas e institucionais, mas buscando reconstruir suas práticas a partir de uma perspectiva singular, recuperando os nomes e os pequenos rastros deixados pelas mulheres internadas.

\section{Resultados}

\section{Pretas}

Foram encontrados 9 prontuários de mulheres identificadas como "pretas". Entre elas, Rosalina Francisca da Conceição, 40 anos, viúva; Christina Conceição, 40 anos, casada; e Constança Rosa, 25 anos, solteira, que compartilhavam com Júlia Maria da Conceição (de 30 anos e também solteira) a condição de domésticas e o 
diagnóstico de alcoolismo ou sua variação, a psicose alcóolica, que não aparece em nenhuma mulher branca. Ao ser internada, a viúva Rosalina era uma das únicas internas que possuía em cofre alguns "bens": "Um par de brincos de moedas, dois rosários de contas, um colar ordinário com 4 berloques, 4 santinhas, um broche quadrado, um anel ordinário, uma chave, um cordão ordinário".

Quem também possuía algum valor no cofre da instituição (muito pouco, 400 réis) era Júlia Maria, de 30 anos, também preta, solteira e doméstica, também internada como alcoolista. Segundo os apontamentos do médico-legista Sebastião Côrtes, Júlia é de baixa estatura, de sensibilidade gentil e corpulência regular. Possui "estygmaphysico" de depressão, motilidade interrompida, tensão nas extremidades dos dedos, a língua "volumosa”; e a falta de dentes. É dito que não tem noção do tempo, que possui alucinações visuais e auditivas. A nutrição é regular, ela sofre de insônia e sua memória é descrita como perturbada. Desorientada, tem alucinações e delírios do sonho. Ela será diagnosticada tanto por Sebastião Côrtes (médico-legista da polícia), como por Henrique Roxo (do Pavilhão de Observação do hospital) como alcoolista, já o médico Sampaio, do Hospital Nacional, diagnosticará epilepsia.

Júlia foi encaminhada ao hospício pela Santa Casa da Misericórdia e consta que a paciente "nunca teve qualquer moléstia", mas que "faz uso de bebida alcoólica". Ela terá alta em 1914 e, no exame realizado no Hospital Nacional em 1911, apresenta-se “calma e com physionomia preocupada”. Seu prontuário é um dos mais preservados e revela que a ficha a ser preenchida pelo médico legista, impressa em uma folha de papel ofício, já indicava de forma detalhada tudo o que deveria ser pesquisado no exame diagnóstico.

Foucault vai dedicar uma importância particular ao exame em suas diferentes formas históricas, vendo nele uma técnica disciplinar onde se entrelaçam o saber e o poder (Castro, 2009), combinando as técnicas da hierarquia que vigia e as da sanção que normaliza em uma vigilância que permite qualificar, classificar e punir. Ritualizado e meticuloso, o exame estabelece sobre os indivíduos uma visibilidade através da qual eles são diferenciados e sancionados. Através dele não só se institui uma verdade acerca do que quer que seja, como também se prescrevem técnicas, procedimentos, práticas, reunindo assim um receituário moral para contenção do "mal" (Foucault, 1991).

No caso do Hospital Nacional de Alienados, a primeira parte deste exame era uma anamnese, que investigava os antecedentes familiares, acidentes, doenças na infância, puberdade, idade adulta e as informações sobre ascendentes e colaterais. Em seguida, o exame passa a ser "directo", e se concentra na atitude, apresentação fisionômica, mimica falada e atuada do paciente.

Depois disso, a indicação é de que o exame passe a ser "somático" e investigue a altura, a "corpulência, desproporção, vícios de conformação" do paciente. Da cabeça devem ser observadas: "forma; deformações; asymetrias; face: desvios, contracções, tremores; cicatrizes; pragmatismo; olhos; língua; boca; nariz; anomalias e malformações". No corpo, os formatos "thoracicos e pelvianos, inversões visceraes. 
Sensibilidade. Motilidade. Reflexos". Por fim, deve investigar ainda a "falla: escripta; caracteres; significado (uso de paradigmas) ".

A terceira e última parte do exame, o "Exame mental pelo interrogatório e observação de actos e palavras do examinado" indicava que deveriam ser observados a noção de tempo, lugar ou meio, confusão do espírito, alheamento ao meio exterior, humor, associação de ideias, apatia ou delírio, transformações da personalidade, depressão, angústia, percepção, inteligência, atenção voltada para si e para os outros.

As características do exame psiquiátrico também serão discutidas por Engel (2001), que identifica nas minuciosas investigações sobre a vida dos pacientes e de suas famílias e no igualmente meticuloso escrutínio somático, a necessidade dos psiquiatras em corroborar, "provar" a loucura, tornando de alguma forma a anormalidade visível. Este exame, que para os psiquiatras desvendaria os sinais inequívocos de degeneração, era somático e mental. Um desbravamento total do indivíduo, "nitidamente inquisitorial" (2001: 151), que incluía ainda elementos como posição social, educação e a cultura intelectual do paciente, além dos sinais habituais que comprovam sua morbidade e traços degenerativos.

Citando os trabalhos de Henrique Roxo, Engel aponta as orientações gerais que deveriam ser observadas:

Exercitando sua capacidade de apreender e interpretar os menores e mais imperceptíveis detalhes, o observador deveria, primeiramente, assinalar o aspecto geral do doente - sua configuração, estatura etc. - e definir sua fisionomia - expansiva, deprimida ou sem qualidades distintivas -, bem como o seu estado - calmo ou agitado, alegre ou triste -, atentando-se para o modo pelo qual ele respondia às perguntas (Engel, 2001: 145).

Nos registros sobre a constituição familiar das pacientes, é interessante notar que todas as mulheres pretas têm a filiação dada como ignorada. O mesmo não ocorre no grupo das brancas e pardas, em que algumas possuem referências familiares maternas ou menções a cunhados ou irmãos. Entre as "pretas", apenas Christina é casada; e Rosalina e IlydiaMathildes da Conceição, viúvas.

Segundo Soihet (1989), isso poderia ser interpretado como o não reconhecimento de formatos familiares diversos, de uniões não registradas ou temporárias, muito comuns nas classes populares e que passam a ser combatidas nas primeiras décadas da república. De fato, ali se constitui um modelo público de moralidade, com papéis heteronormativos muito bem definidos e onde a mulher é um vetor fundamental na promoção da saúde física e mental da família, "garantindo uma prole saudável e uma futura classe dirigente sólida e respeitosa das leis, das regras, dos costumes e das convenções (...). A divisão de esferas fica marcada _o homem na órbita pública e a mulher na privada" (Soihet, 1989: 113). Os modelos familiares que não se inscrevem no padrão serão automaticamente marginalizados. 
Neste aspecto, é notável também a ausência do registro das proles, embora alguns relatórios localizados no Arquivo Nacional registrem a transferência de pacientes da colônia para as enfermarias do Hospital Nacional de Alienados, para que lá pudessem ter seus filhos (Arquivo Nacional 1911-1918).

Josepha Antônia dos Santos, 30 anos, solteira e doméstica, vinha do Asylo de Menores Abandonados e Lucia Maria (sem sobrenome), 38 anos, também solteira e doméstica, não tinha residência. Josepha e Lúcia, assim como todas as outras mulheres "indigentes", fossem brancas, pretas ou pardas, com residência ou não, com qualquer diagnóstico, haviam sido internadas pela Secretaria de Polícia do Distrito Federal. Como já foi falado, desde o século XIX o controle da condição perigosa do "doido" e o exercício das limitações impostas pelas práticas higienistas serão objeto da polícia médica, diretamente subordinada às câmaras municipais (Machado, Loureiro, Luz \& Muricy, 1978).

No caso de Josepha Antônia, a tutela da polícia se fez ainda mais presente. Ela dá entrada 5 vezes no Hospital Nacional de Alienados e somente depois da quarta internação seu diagnóstico é confirmado. Entre estas internações, o delegado Rego Braga faz uma solicitação em carta manuscrita, "no sentido de ser entregue ao portador deste, a nacional Josepha Antonia dos Santos que ahi se acha com alta conforme o vosso officio DR 126 de anteontem", dando a entender que a polícia não apenas internava, como também era responsável por fazer o deslocamento entre a instituição asilar e o hospício, nas altas e nos retornos à instituição psiquiátrica.

Em relação às altas, conforme visto em correspondências trocadas entre o diretor do Hospital Nacional, o chefe da polícia e o Ministro de Negócios Interiores, havia discordâncias entres os representantes dessas três instâncias. Em 1913, o Chefe da Polícia escreve ao Ministro e ao diretor do Hospital Nacional reivindicando providências pelo número de "bebedores habituales" que saíram do Hospital Nacional com alta e voltavam a "cometer desatinos" nas ruas. Juliano Moreira (diretor do hospital) responde às duas instâncias afirmando não concordar com a longa internação dos "alcoolistas" junto aos demais doentes e sugere intervenções específicas para esses casos, como a criação de colônias para essa população e uma taxação de impostos sobre as bebidas alcóolicas que pudesse ser revertida para os cuidados necessários. Tais documentos confirmam o quanto esses três poderes, Estado-Polícia-Psiquiatria, estavam interligados e somando esforços para organizar e normatizar o espaço urbano segundo os preceitos higienistas e eugênicos (Arquivo Nacional, 1911-1918).

Marcellina Eva (sem sobrenome), 25 anos, doméstica e casada; e Felismina da Conceição, de 22 anos e solteira, dão entrada na instituição com o diagnóstico de demência precoce. Marcellina é internada na Colônia, vinda do Hospital de Alienados em 1911 e obtém alta em 1913, não havendo mais registro de seu retorno à instituição. De modo diferente, Felismina tem sua transferência para a colônia deliberada em 4 de julho de 1911, mas ela se efetiva apenas em 5 de setembro deste mesmo ano, o que nos leva a pensar que o processo de transferência de algumas internas começa a ser articulado muitos meses antes de sua implementação. Assim como no caso de 
Josepha, esta não havia sido a primeira internação de Felismina. A primeira foi em 1902, no Hospital Nacional, quando a paciente tinha apenas 13 anos, e a última em 1910, quando finalmente é analisada no pavilhão de observações e diagnosticada com demência. Estes dados nos levam a concluir que as internações podiam obedecer a um ritmo intermitente e que as pacientes eram periodicamente reavaliadas.

Essa intermitência também é observada no percurso asilar de Lúcia Maria, que recebe o diagnóstico de "psy-periódica - forma depressiva”, com duas entradas no hospício; de Josepha Antônia dos Santos, que dá entrada no Pavilhão de Observações por 5 vezes; de IlydiaMathildes da Conceição, que recebe o diagnóstico de "psychose infectuosa" (malária), internada duas vezes; e de Rosalina Francisca da Conceição. Esta última, internada com o diagnóstico de alcoolismo, também passa por duas vezes no Hospital Nacional e chega à colônia em 16 de dezembro de 1911, internada pelo alienista Paulo Costa. São seis as suas idas e vindas na Colônia entre 1923 e 1929. Depois disso ela só irá sair em 1939 para tratar uma tuberculose, retornando no mesmo ano, sem registro de alta ou morte.

IlydiaMathildes também fazia uso de bebida alcoólica, só que de forma mais moderada. No resultado de sua anamnese, realizada pelo doutor Pereira das Neves do Hospital da Misericórdia, aparecem os seguintes sintomas: estigma físico de dependência, língua muito saburrosa e sua "corpulosidade gulosa”, eles confirmariam o diagnóstico de "psychoseinfectusa". Para o médico Sampaio, do Hospital Nacional, aqueles que mais chamaram a atenção, ou "a summa das acquisições que denunciaram a doença", foram sua falta de noção do tempo, seu humor tristonho e sua percepção confusa; seus tremores físicos. Sua fisionomia e gestos anêmicos, seu estômago flatulento e sua voz rouca. Ela confirma o uso de bebida e o médico lhe atribui ainda a presença de alucinações auditivas e ideias delirantes, dando um diagnóstico idêntico ao que já fora dado pela polícia. Ilydia será examinada ainda uma outra vez, agora no Pavilhão de Observação, pelo alienista Sebastião Côrtes. Neste exame, apesar de serem identificados sintomas muito parecidos como percepção demorada, falta de percepção do tempo, humor triste e o uso de uma "nutrição irregular", o diagnóstico será o de "confusão mental”.

\section{Brancas}

Enquanto entre as mulheres pretas o diagnóstico mais comumente encontrado será o de alcoolismo, entre as "brancas" ele será mais heterogêneo. Maria Hermínia de Souza Ramos recebe o diagnóstico de epilepsia. Ethestina da Cruz, Joaquina de Freitas e Júlia César Guimarães serão consideradas loucas ou psicóticas maníaco-depressivas. Júlia, solteira de 25 anos, se apresenta ao médicolegista de forma calma, que ele descreve como uma "physionomia anímica". Chama ainda a atenção dele a sua baixa estatura e corpulência, sua nutrição gulosa, sua insônia, e aquilo que ele denomina de "estigma physico de depressão", que se desvela 
em seu "humor assustado, suas ilusões com delírios de perseguição e sua falta de noção do tempo e desorientação". Já no Hospital, em exame realizado no Pavilhão de Observações chamarão a atenção do médico Henrique Roxo a desorientação espacial, sua atitude assustada e a estatura, mas ainda serão dignas de nota suas faces expressivas, seu humor alegre, seus leves tremores na língua e nos dedos. O mesmo Henrique Roxo identifica ainda que a paciente possui uma inteligência mediana e mantém a memória conservada, bem como "a percepção e associação de ideias regulares".

No caso de Joaquina de Freitas, viúva de 45 anos, os sintomas que a levam à internação como maníaco-depressiva são os mesmos delírios de perseguição, tremores na língua e nos dedos, seus "reflexos em geral exaltados", sua "percepção e associação de ideias anormais, seu humor muito alegre", bem como seu "estygma de degeneração". Em função de seu estado de "agitação contínua”, será considerada inapta para o trabalho na colônia e voltará ao hospital em 1912, onde morrerá em 1913.

Apesar das semelhanças, no prontuário de Joaquina haverá uma diferença com relação ao de Júlia. Nele existem algumas anotações feitas pelos médicos Paulo Costa, do Hospital Nacional de Alienados; Sebastião Cortês, da Colônia e Henrique Roxo, do Pavilhão de Observação, que colocam em questão o diagnóstico de psicose maníaco depressiva. É colocada (acompanhada de um ponto de interrogação) a possibilidade do diagnóstico ser de "hysteria". O mesmo acontece no prontuário de Idalina Noronha, diagnosticada pelo médico da polícia Jacyntho Barros com "excitação maníaca" e por Henrique Roxo no Pavilhão de Observações com "psychose periódica”.

Essas questões refletem bem as mudanças pelas quais o pensamento psiquiátrico brasileiro atravessava no período. Segundo Birman (2010) e Garcia (1995), a tendência a se diagnosticar com mais frequência a demência precoce e a psicose maníaco-depressiva no lugar da histeria se deve à solidificação dos paradigmas teórico e clínicos de Kraepelin, que se expandem às custas da consequente e correlata redução do campo clínico da histeria que fora estabelecido pela tradição francesa. A imediata consequência disso é o peso etiológico que passa a ser conferido à degeneração hereditária e à constituição biológica dos sujeitos na interpretação das inquietações mentais, deixando de lado os fatores circunstanciais, singulares e históricos da experiência de vida de cada um deles no diagnóstico das enfermidades.

O mesmo acontece com o diagnóstico de psicose periódica, que aparece nos prontuários de Idalina e também no de Joana de Jorge Massane. Ainda segundo Birman (2010), foi o conceito de psicose periódica, elaborado por Kraepelin em 1899, que circunscreveu tanto os estados de transição quanto as relações existentes entre as crises maníacas e melancólicas, sustentando a existência de um processo, englobando "todas as psicoses anteriormente descritas - chamadas de intermitente, circular, periódica, de dupla forma e alterna - em uma enfermidade fundamental denominada loucura maníaco-depressiva, passando a considerá-la uma "psicose endógena”, isto é, de ordem essencialmente constitucional” (Birman, 2010: 351). 
Para Kraepelin, a etiologia das perturbações mentais poderia ser exógena, quando sua causa está fora do organismo; ou endógena, quando está nele, como é o caso da demência precoce, da psicose maníaco-depressiva ou da psicose periódica. Por uma ordenação "essencialmente constitucional", deve-se compreender uma forma de funcionamento mental absolutamente vinculada aos processos biológicos, orgânica no sentido de uma causação física da organização mental:

“(...) a oposição endógeno/exógeno tinha uma funcionalidade operacional na leitura de Kraepelin (1927). Com efeito, enquanto as enfermidades exógenas seriam relativamente reguláveis e curáveis, as endógenas, em contrapartida, estariam fadadas à cronicidade, uma vez que enraizadas num fundo constitucional e degenerativo." (Birman, 2010: 349)

O caso de Alexandrina Rosa da Silva ilustra bem tanto a mudança nos diagnósticos e nas ideias acerca da causa das enfermidades, quanto este fundo constitucional presente na etiologia proposta por Kraepelin. Alexandrina, de 20 anos, deu entrada na secretaria de polícia do Distrito Federal em setembro de 1911, onde foi examinada pelo legista Jacynto de Barros, que lhe atribui debilidade. Entretanto, examinada por Henrique Roxo no Pavilhão de Observação do Hospital Nacional, onde passa três dias, será diagnosticada com histeria por conta de seus estigmas de degeneração e suas ideias pueris.Alexandrina chega à Colônia em 1912, quando é examinada pelo médico legista Miguel Salles que se apoia neste mesmo fundo "essencial” em sua diagnose. Na anamnese que realiza também são observados os mesmos estigmas de degeneração, finalmente especificados como sendo: estrabismo no olho direito, o hábito de roer unhas e a "implantação viciosa" de seus dentes. Será observada ainda sua expressão fisionômica variável, "ora risonha, ora triste e indiferente", que lhe custará a atribuição de "humor instável, perversão de caráter, tendência à simulação, e apoucamento do nível intelectual”. Mas, antes de chegar no Engenho de Dentro, teria passado ainda pelo Hospital Nacional de Alienados, onde se sabe que tem pai vivo, que perdeu a mãe há quatro meses, vítima de parto, que tem muitos irmãos e que nenhum deles sofre de doença mental.

Desde então ela está sob os cuidados do asilo Bom Pastor onde, segundo informações da superiora, tem tido crises noturnas de agitação, perturbando o silêncio da casa. Se apresenta calma, orientada, entende sua situação passada quando ainda vivia com a mãe e a atual, "sua aparência, seus actos revestem-se de um cunho de infantilidade: traz por exemplo uma boneca ao collo e procura escondê-la. ”. Depois de passar pela colônia, Alexandrina retornaria mais uma vez ao Hospital através de um ofício do próprio diretor da colônia, o alienista Simplício de Lemos Braule Pinto, que menciona sua incompatibilidade com o regime de um hospital aberto. É transferida pela última vez para uma instituição em 1916, quando retorna para o asilo Bom Pastor, onde não permanecerá "por não mais se justificar sua permanência naquele estabelecimento”. Buscada por um parente, sabe-se por correspondência do 
Hospital Nacional que a paciente saiu do asilo um mês depois de sua chegada e que se encontrava sob o regime da assistência heterofamiliar.

No hospital ela foi minuciosamente medida e examinada. Mensurações que vão desde as mais esperadas como sua "forma craneana", peso e altura, àquelas que parecem mais inusitadas como medida das mãos e de sua força "dynamometrica", medida das orelhas, dos pés, do dedo médio, do mínimo, das coxas e pernas. $\mathrm{O}$ princípio que analisa, que seleciona o que é relevante ou não na circunscrição da sintomatologia de Alexandrina, parece refletir esta passagem de filiação da psiquiatria brasileira do início do século XX. O diagnóstico aqui realizado não se faz constatando os efeitos da doença mental sobre o corpo, tal como na tradição de Charcot, onde os sintomas físicos da histeria decorrem de certas disposições e de um estado particular do sistema nervoso e onde as debilidades hereditárias ou constitutivas generalizadas não fazem qualquer diferença (Rubin, 2017).

Idalina, que havia sido transferida para a colônia em dezembro de 1911, nada informava sobre sua família ou sobre seu passado, embora os nomes de seus pais constassem na ficha de internação. Não possuía nenhum bem ou documento. Tinha a estatura média e uma compleição forte, trauma nos dedos e apresentava uma atitude humilde. Na polícia, atendida pelo médico legista Jacyntho Barros, que dianosticará a "excitação maníaca", chamaram a atenção sua fuga de ideias, seus pensamentos "alucinantes de caráter persecutório", seu humor humilde e sua incapacidade de explicar as causas de sua internação. Já o diagnóstico feito por Henrique Roxo no Hospital Nacional de "psychose periódica" se baseou na observação de suas ideias "pueris", de sua emotividade exagerada, sua desarticulação quanto ao espaço e ao tempo e "suas simpatias e antipatias imotivadas".

Idalina, assim como acontece com todas as mulheres brancas e todas as mulheres pardas e negras, é descrita como “doméstica”. Importante ressaltar que, fora das colônias, muitas mulheres executavam serviços que não eram reconhecidos pelo Estado, e por conta disso eram perseguidas e proibidas de exercê-los em nome de uma higienização e modernização do espaço público (Soihet, 1989). De forma diferente, dentro delas, o trabalho das pacientes em atividades como as de agricultura, avicultura, colchoaria ou cozinha será enaltecido e descrito em um relatório de 1912 pelo diretor da colônia Braule Pinto como "indispensável” (Arquivo Nacional (1911-1918). Segundo Soihet (1989), apesar de haver evidências de que uma parte representativa das mulheres viviam reclusas e que (muitas vezes não por vontade própria) cultivavam a ociosidade; é certo também que outra parcela delas, as mais humildes, contribuíam economicamente para o sustento familiar, trabalhando como lavadeiras, doceiras, costureiras, babás. Atuavam também nos pequenos teares domésticos e nas indústrias desde meados do século XIX. Lutavam junto com os homens por melhores salários e jornadas de trabalho menores, mas suas conquistas quase sempre eram menores e suas tarefas não possuíam qualquer reconhecimento, nem lhes garantia promoção social (Teles, 2017).

Esse trabalho compulsório, justificado como meio de economia para o Estado, fazia com que as pacientes fossem vistas como suas empregadas e responsáveis pela 
manutenção da colônia. Em relatório destinado ao ministro dos negócios interiores em 1913 (Arquivo Nacional 1911-1918), Braule Pinto compara o início do funcionamento da colônia ao início de qualquer empresa, narrando que ainda não havia sido possível alcançar os resultados econômicos que se esperavam dela. Isso explicaria as "licenças" que são oferecidas a algumas pacientes, como é o caso de Maria da Costa, de 26 anos, que recebe uma autorização de saída, prorrogada por duas vezes, mas que acaba sendo "eliminada" do hospício por não ter regressado no prazo estipulado. Da mesma forma Maria Ignez de Pinto, de 38 anos, solteira, diagnosticada com histeria, que sai com 6 meses de licença em 1912 e também acaba por ser "eliminada” por não ter se apresentado na data marcada.

\section{Pardas}

Foram localizados 5 prontuários de mulheres designadas como "pardas". Destas, três falecem de tuberculose pulmonar: Maria da Conceição Dias, de 25 anos, que ficou 6 anos internada; Margarida dos Santos, de 21 anos, que passou 11 anos; e Celeste dos Santos Piedade, que permaneceu 12 anos internada. Pelo registro das transferências realizadas, Margarida dos Santos, atendida por Plínio Olinto, recebe um encaminhamento de retorno ao Hospital Nacional "por ser tuberculosa". O mesmo acontece com Maria da Conceição, que é transferida para o Pavilhão "Simoni" (sic), no Hospital Nacional, por conta de uma "provável" tuberculose.

No Brasil das primeiras décadas do século XX, quando as populações começam a se adensar nos grandes centros urbanos, a tuberculose torna-se um grave problema de saúde pública, seja em função de suas altas taxas de mortalidade, seja por sua persistência e propagação particularmente entre as populações desfavorecidas. A partir de 1920, quando a doença passa a ser identificada de forma mais clara, a implantação de condutas profiláticas e terapêuticas começa a ganhar maior repercussão (Maciel, et al, 2012). De forma afinada a estas novas orientações, nas transferências registradas nos prontuários é possível notar que, ao ser identificada a doença, as pacientes imediatamente saíam da Colônia e retornavam ao Hospital Nacional, onde eram internadas em pavilhões específicos de tuberculosos, o DeSimoni e o Sigaud (Engel, 2001).

Conforme Silva (2017), 42\% das pacientes que haviam sido transferidas para a Colônia de Alienadas acabaram retornando ao Hospital Nacional por conta de dois motivos principais: $63 \%$ por incompatibilidade ou não-adaptação ao regime colonial e $\mathbf{2 0} \%$ por necessidades médico-hospitalares, entre as quais o tratamento da tuberculose ( $9 \%$ das doentes). Segundo a autora, este dado ratifica o surgimento da colônia não como uma instituição hospitalar, mas sim como um local para onde deveria ser enviada a parte do excedente de mulheres da instituição central que pudesse trabalhar. Já a inadaptação ao trabalho abarcava, principalmente, a inadequação ao serviço braçal ou a agitação por parte das pacientes. Dentre aquelas 
que não se adaptaram ao regime colonial está Júlia Luiza de Carvalho, de 17 anos, que permanece apenas um ano internada. Em seu prontuário há uma correspondência do diretor Braule Pinto narrando o desajuste de Júlia e de mais uma paciente, Elisa Antunes da Silva, ao trabalho na colônia. Nessa correspondência, ele solicita ao diretor geral da assistência, Juliano Moreira, a imediata transferência das duas para o Hospital.

O prontuário de Elisa não pôde ser localizado, mas o de Júlia nos diz que ela foi internada pela primeira vez em 1903, aos nove anos de idade, com o diagnóstico de debilidade mental. Depois disso, retornará ao hospital em 1911, sendo transferida para a Colônia logo em seguida. Nesta última internação, que durará um ano, recebe três diagnósticos diferentes, o de psicose maníacodepressiva pelo alienista Paulo Costa; de epilepsia, por Sebastião Côrtes; e debilidade mental, por Henrique Roxo. Sua ficha contém ainda inúmeras medidas do corpo, realizadas pelo serviço de antropometria do Hospital Nacional como altura, peso, busto, dentre outras. Seu exame somático identifica estigmas de degeneração e tremores nas extremidades dos dedos; o exame mental, confusão e leve tensão. Ao chegar ao hospital, possuía 340 réis e um par de luvas, que foram guardados no cofre; parecia calma, "tinha as pupilas semi-seladas, com a physionomia do sonho".

Quem também recebe o diagnóstico de debilidade mental é Margarida dos Santos, doméstica, solteira, nada possuía em cofre e nunca sofreu qualquer "ataque". Em seu exame apresentou-se calma e com a fisionomia expressiva. Em função de "sua atenção difícil", de sua memória levemente perturbada, de suas desorientação e confusão, das ideias vagas e dos "estigmas histéricos", será diagnosticada com debilidade mental no Hospital Nacional e como histérica na polícia e no Pavilhão de Observação. Apresenta, assim como quase todas as mulheres sejam pretas, brancas ou pardas, o onipresente "estigma de degeneração". No "diagnóstico ou resenha symptomática feita no Pavilhão", serão destacados ainda seu humor irritável, suas alucinações auditivas e visuais; além das marcas de varíola e de queimadura.

A última das mulheres nomeadas como "pardas" é Thereza da Rocha Borges e, dela, não há registro de morte ou alta. Diferente de todas as demais mulheres classificadas como pardas, Thereza tem em sua ficha de entrada no hospital o nome do pai e o nome da mãe, e ao chegar ao hospital trazia consigo uma aliança. Ela, assim como Maria da Conceição Dias e Celeste dos Santos Piedade, receberá o diagnóstico de demência precoce, ratificando também nas mulheres pardas, a tendência a se diagnosticar com mais frequência a demência precoce e a psicose maníaco-depressiva no lugar da histeria, confirmando a consolidação dos paradigmas teórico e clínicos da escola alemã de psiquiatria. 


\section{Discussão}

O conceito de interseccionalidade, proposto como dispositivo de análise neste artigo, estabelece uma compreensão das relações de gênero que captura "as consequências estruturais e dinâmicas da interação entre dois ou mais eixos de subordinação" (Crenshaw, 2002: 177). Eixos como o racismo, o patriarcalismo ou a opressão de classe, entre outros sistemas de discriminação, que se institucionalizam e se relacionam na criação da desigualdade e da violência.

$\mathrm{O}$ estudo deste enlaçamento permitiria compreender as singularidades geográficas e histórica das formas de subordinação e suas respectivas dinâmicas de opressão, em particular como foi distribuído o peso das questões raciais, classistas ou patriarcais a cada evento analisado. Além disso, explicitaria o traçado irregular e confuso das fronteiras entre saber e poder que constituirão o discurso científico, questionando sua pretensa inviolabilidade e localizando sua origem e produção em um contexto social muito mais amplo.

No caso específico deste trabalho, pode-se dizer que as variáveis de gênero e classe se definem a priori pela própria condição do grupo pesquisado. São mulheres diagnosticadas como loucas e que, por não poderem arcar com os custos de sua internação no Hospital Nacional, são transferidas para a colônia agrícola do Engenho de Dentro. Nesta instituição, serão obrigadas a trabalhar e pagar o seu tratamento e estarão submetidas a um dispositivo disciplinar que as isolará para fora do espaço urbano.

Entretanto, é impossível não ressaltar também a questão racial, que se impõe como "espinha dorsal" (Lima, 2017:71) para o debate interseccional e o resgate da história da institucionalização dessas mulheres e da própria criação da Colônia de Alienadas. Apesar de Juliano Moreira, negro e nordestino, diretor do Hospital Nacional e diretor da Assistência Médico-Legal de Alienados, já estar voltado para o desenvolvimento da psiquiatria como prática assistencial pública e como conhecimento científico médico (Venâncio \& Carvalhal, 2005), a psiquiatria neste momento ainda é classificatória e normativa (Amarante, 2013). Funcionava em um contexto marcado pela hegemonia de uma cultura profundamente escravocrata e patriarcal, no qual este recém constituído saber psiquiátrico precisava se inserir a fim de se consolidar como força política reconhecida.

Neste sentido, pode-se afirmar que o discurso psiquiátrico construiu uma forma de racismo científico, classificando como prática médica, cientificamente legitimada, aqueles dispositivos utilizados para enquadrar a população negra em "subraça” (Barros et al, 2014). Ratificando que "a abolição da escravatura não significou de forma alguma a libertação do povo negro. Pelo contrário, acentuou-se sua condição de marginalizado" (Teles, 2017: 41). Associando a noção de periculosidade social ao conceito de doença mental e propiciando uma sobreposição entre punição e tratamento. 
Referindo-se aos processos de desumanização pelos quais os homens negros são submetidos, Fanon (2008) categoriza esse lugar de marginalização, de exclusão da humanidade como zona do não-ser. Este lugar, habitado por homens e mulheres negras, é descrito pelo autor como "uma região extraordinariamente estéril e árida" (Fanon, 2008: 26), que é relegada ao silenciamento por aqueles que pertencem a "zona do ser": os colonizadores brancos, os definidores do absoluto e dos critérios do que venha a ser humanidade, que criam e atualizam os mecanismos mantenedores dessa ordem hierárquica de poder.

Como exemplo deste processo de desumanização pode ser citado o trabalho apresentado pelo psiquiatra Henrique Roxo no Segundo Congresso Médico LatinoAmericano, ocorridona Argentina, em 1904 (Mathias, 2017). Publicado no Brasil Médico em 1904, seu trabalho intitulado "Perturbações mentais nos negros do Brasil" busca relacionar doença mental e raça. Por mais que os dados levantados demonstrem que naquele período os negros não eram a maioria nos hospícios do Brasil, Henrique Roxo utiliza-se de artifícios biologizantes para ainda assim legitimar a ideia propagada de inferioridade da raça negra. Ele os justifica argumentando que o cérebro dos negros "não evoluiu de modo completo" e por isso "gastam menos o cérebro que os brancos" (1904: 171-172), o que os torna pouco suscetível ao desenvolvimento de doença mental. Além disso, segundo o psiquiatra, a "imbecilidade" está presente em todos os negros internados nos hospícios e faz parte dos "atributos da raça que não evoluiu", pelo cérebro não comportar "grandes expansões intelectuais" (1904: 181). Nos prontuários localizados, esse ideário biologizante estará presente nas investigações sobre a vida dos pacientes e de seus ramos familiares e na necessidade de corroborar os traços degenerativos, compostos por qualquer traço físico ou cultural dissonante.

Henrique Roxo também expressa o pensamento socialmente difundido acerca da mulher categorizada como "preta" nos prontuários. No seu estudo, o número de mulheres negras internadas é maior que o de homens negros internados. Nesse caso, o alienista reconhece a influência de fatores sociais na origem da alienação mental, destacando a abolição da escravatura. Segundo ele, a libertação "dessas pessoas" "da noite para o dia” significou um grande número de pessoas em condição miserável nas ruas, os tornando dependentes daquele que "superiores em evolução, lhes podiam propinar trabalho e pão” (Roxo, 1904: 171). Seguindo essa linha de pensamento, Roxo (1904) argumenta que a causa do número maior de mulheres pretas internadas devia-se ao fato de suas atividades serem menos intensas e por não possuírem uma “organização familiar”. Ainda segundo Roxo, por conta destas características, estas mulheres eram mais propensas a se entregar "ao álcool e a devassidão" (idem).

Será através destas construções discursivas, afinadas com o pensamento biologicista e com a tradição colonial e escravocrata, autointitulada "superior" e suposta provedora "do trabalho e do pão", que o racismo-científico ocupará seu lugar social e político no imaginário da primeira república. Percebe-se que os conceitos e as práticas psiquiátricas, em consonância às forças sociais mais opressivas, longe de identificar e tratar dos problemas sociais enfrentados pela população pobre e negra, passam a ver nestas pessoas e em suas formas de existir o próprio problema a ser 
eliminado ou institucionalizado (Gordon, 2008). É o caso do alcoolismo identificado apenas entre as mulheres "pretas", diagnóstico descrito por alguns alienistas como perigoso ou como"moléstia social", sendo alvo de grande repressão policial (Arquivo Nacional, 1911-1918). Através dos prontuários, identifica-se a continuidade das internações das alcoolistas como uma prática que o Estado demandava às instituições psiquiátricas, a fim de conter e isolar uma parcela muito específica da população.

Estas construções parecem corroborar a ideia de Crenshaw (2002: 179) de uma "subordinação interseccional estrutural", ou, nas palavras de Fanon, do "arsenal de complexos germinados no seio da situação colônia” (Fanon, 2008). Confirmam a presença de defasagens e desigualdades históricas e a marginalização de toda manifestação cultural e social singular das classes mais populares. No rol deste silenciamento podem ainda ser listadas as diferentes formas de constituição familiar, que no caso das negras não são reconhecidas; bem como as diversas formas de trabalho, de formas de geração de renda que sustentavam o cotidiano das mulheres brancas, pardas e pretas, que lhes ofereciam uma identidade, e que a partir da entrada no hospício passam a ser desconsideradas e designadas sob a forma geral de "ocupação doméstica”.

Nesse mesmo campo de domínio cumpre ressaltar ainda o papel de outra instituição, a policial, que atua de forma direta com o hospício e com o asilo de menores. Ela é a força responsável pela internação de todas as mulheres pobres. Pode-se comparar a polícia como responsável por manter a ordem no espaço público com o que Fanon (1968) expõe sobre o papel do gerdarme ou "soldado" nas colônias. Estes são vistos como porta vozes do colono e do regime de opressão, atuando como intermediários do poder por meio de suas intervenções frequentes e diretas. Essas ações são marcadas por uma linguagem de pura violência, incidindo sobre o corpo marginalizado com o objetivo de contê-lo, paralisá-lo (Fanon, 1968). Nesta função, esses mediadores do poder são peças chave para manter a segregação dos espaços e a condenação dos corpos que ameaçam o projeto de modernização pautada nos moldes de civilização da burguesia branca européia.

\section{Considerações Finais}

Como já foi dito, neste trabalho o objetivo central foi descrever e analisar as práticas e os dispositivos psiquiátricos destinados às mulheres pobres nas primeiras décadas da república brasileira. Pretendeu-se compreender o que era caracterizado pela psiquiatria da época como sendo a loucura feminina; bem como refletir sobre como esta conceituação interage com outros discursos que definem este período histórico. Tendo a psiquiatria como uma força essencial na nova configuração republicana, buscou-se circunscrever as demandas, as exigências específicas de regulação social e moralidade, que estes discursos recém instaurados vão dirigir às instituições asilares. 
Para tanto, foram analisados 24 prontuários das primeiras pacientes que foram transferidas do Hospital Nacional para a Colônia de Alienadas ado Engenho de Dentro. Foram consultados ofícios, relatórios e correspondências no Arquivo Nacional referente a essas instituições no início do século XX. Além disso, foram também pesquisadas as análises feitas por Henrique Roxo no Pavilhão de observações, que constam em documentos abrigados no Instituto de Psiquiatria da Universidade Federal do Rio de Janeiro.

Como também já foi falado, o conceito operador da análise dos dados bibliográficos e da pesquisa das fontes primárias foi o de interseccionalidade, categoria que incorpora um dos eixos centrais da epistemologia feminista contemporânea. Este conceito opera articulando diferentes categorias e marcadores sociais, tais como raça e classe, à categoria de gênero e analisa suas interações na produção e na reprodução das disparidades sociais (Henning, 2015).

As observações trazidas pelo campo corroboram a concepção interseccional, confirmando os engendramentos das opressões de gênero, classe e raça no processo de internação das mulheres. Neste trabalho, o entendimento do modo como os marcadores sociais da diferença se relacionam é fundamental em dois sentidos. No primeiro, para compreender como os ideais republicanos se estruturaram e se propagaram, servindo de base para a construção de um sistema desigual de poder. No segundo, para compreender a constituição do pensamento psiquiátrico no Brasil como classificatório e normativo (Amarante, 2013), marcado pela hegemonia de uma cultura profundamente escravocrata e patriarcal, na qual ele precisava se inserir para se consolidar como força política reconhecida.

\section{Referências Bibliográficas}

AMARANTE, Paulo. (2013) Saúde mental e atenção psicossocial. R.J.: Fiocruz.

(2016). Loucos pela vida. R.J. Fiocruz.

ARQUIVO NACIONAL. (1911-1918). Série Saúde.Ofícios, processos e relatórios. IS³. RJ.

BARROS, Sônia; BATISTA, Luís Eduardo; DELLOSI, Mirsa Elizabeth; ESCUDER, M. M. L. (2014) Censo psicossocial dos moradores em hospitais psiquiátricos do estado de São Paulo: um olhar sob a perspectiva racial. Saúde soc. vol.23 (4), pp.1235-1247. Recuperado em 16 de abril de 2019, de http://www.scielo.br/scielo.php?script=sci arttext\&pid=So104-12902014000401235\&lng=pt\&tlng=pt

BIRMAN, Joel. (2010). A cena constituinte da psicose maníaco-depressiva no Brasil. História, Ciências, Saúde-Manguinhos, 17 (Supl. 2), pp.345-371. Recuperado em 4 de julho de 2019, de http://dx.doi.org/10.1590/S0104-59702010000600005 
BIROLI, Flávia; MIGUEL, Luís Felipe (2005).Gênero, raça e classe. Opressões cruzadas e convergências na reprodução das desigualdades. Mediações. Dossiê Desigualdades e Insterseccionalidades, v. 20, n.2, pp.27-55. Recuperado em 18 de maio de 2020, de https://edisciplinas.usp.br/pluginfile.php/4130753/mod_resource/content/1/ Biroli\%282015\%29\%20Genero\%2oraca\%2oclasse.pdf

BRASIL (1890). Decreto no 181, de 24 de janeiro de 1890. Recuperado em 7 de abril de 2019, de http://www2.camara.leg.br/legin/fed/decret/1824-1899/decreto-181-24janeiro-1890-507282-publicacaooriginal-1-pe.html

CASTRO, Edgard (2009). Vocabulário de Foucault. Belo Horizonte: Autêntica.

CRENSHAW, Kimberlé (2002). Documento para o encontro de especialistas em aspectos da discriminação racial relativos ao gênero. Rev. Estudos feministas v1, 171188.

CUNHA, Maria Clementina Pereira (1989). Loucura, gênero feminino: as mulheres do Juquery na São Paulo do início do século XX. Revista Brasileira de História, 9 (18). pp 124-144.

ENGEL, Magali Gouveia (2001).Delírios da Razão: médicos, loucos e hospícios. Rio de Janeiro 1830-1930. RJ: Fiocruz.

(2002). Psiquiatria e feminilidade In: PRIORE, M. D. (Org.).História das Mulheres no Brasil. SP: Contexto/UNESP.

FACCHINETTI, Cristiana et al. (2010, dezembro). No labirinto das fontes do Hospício Nacional de Alienados. História, Ciências, Saúde - Manguinhos, 17, pp. 733-768. Recuperado em 18 de outubro de 2018, de http://www.scielo.br/pdf/hcsm/v17s2/31. pdf

FANON, Frantz (1968). Os condenados da terra. Rio de Janeiro: Civilização Brasileira (2008). Peles Negras, máscaras brancas. Salvador: EDUFBA

FOUCAULT, Michel (1991). Vigiar e punir. Petrópolis: Vozes. (2006). O Poder Psiquiátrico. S.P.: Martins Fontes.

GARCIA, Carla Cristina (1995) Ovelhas na Névoa. Um estudo sobre as mulheres e a loucura. R.J.: Rosa dos Tempos. 
GORDON, Lewis (2008). Prefácio.In: FANON, F. Peles Negras, máscaras brancas. Salvador: EDUFBA.

HENNING, Carlos Eduardo (2015) Dossiê - Desigualdades e Interseccionalidades. Revista Mediações, v. 20 (2), pp. 97-128. Recuperado em 27 de setembro de 2019, de http://dx.doi.org/10.5433/2176-6665.2015V2on2p97

HIRATA, Helena (2004) Gênero, classeeraça. Interseccionalidadeeconsubstancialidade das relações sociais. Tempo Social, 26(1), 61-73. Recuperado em 28 de agosto de 2018, de https://doi.org/10.1590/So103-20702014000100005

LIMA, Fátima. Vidas Pretas, Processo de Subjetivação e Sofrimento Psíquico: sobre viveres, feminismo, interseccionalidade e mulheres negras. In: PEREIRA, Melissa Oliveira; PASSOS, Rachel Gouveia. Luta Antimanicomial e Feminismos: discussões de gênero, raça e classe para reforma psiquiátrica brasileira. Rio de Janeiro: Autografia, 2017. cap. 3, p. 70-86.

MACHADO, Roberto; LOUREIRO, Ângela; LUZ, Rogério; MURICY, Kátia (1978) Danação da norma: a medicina social e constituição da psiquiatria no Brasil. Rio de Janeiro: Ed. Graal.

MACIEL, Marina de Souza; Mendes, Plínio Duarte; Gomes, Andréa Patrícia; SiqueiraBatista, Rodrigo (2012). A história da tuberculose no Brasil: os muitos tons (de cinza) da miséria. RevBrasClin Med. São Paulo, v.10(3), pp.226-30.

MATHIAS, Cátia Maria (2017). O Pavilhão de Observação na psiquiatria do Distrito Federal: a gestão de Henrique Roxo (1921-1945). Dissertação (Mestrado em História das Ciências e da Saúde) - Fundação Oswaldo Cruz. Casa de Oswaldo Cruz, Rio de Janeiro.

ROXO, Henrique (1904). Perturbações mentais nos negros do Brasil. Brazil Médico, Rio de Janeiro, v. 15, n. 17, p. 156-192.

RUBIN, Claudio Eduardo. (2017). Entre a neuropatologia de Charcot e a psicologia de Bernheim: considerações sobre a hipnose nos primórdios da pesquisa freudiana. Natureza humana,19(1), 102-127. Recuperado em o5 de março de 2019, de http:// pepsic.bvsalud.org/scielo.php?script=sci_arttext\&pid=S1517-24302017000100007\&lng $=$ pt\&tlng=pt.

SANCHES, Daniele Rosa, \&Berlinck, Manoel Tosta. (2010). Debilidade mental: o patinho feio da clínica psicanalítica. Ágora: Estudos em Teoria Psicanalítica, 13(2), 259-274. https://dx.doi.org/10.159o/S1516-14982010000200008 
SILVA, Carine Neves de Alves (2017) Colônia de Alienadas do Engenho de Dentro (1911-1932). XXIX Simpósio Nacional de História ANPUH. Contra os Preconceitos: história e democracia.Recuperado em 8 de julho de 2019, de https://www.snh2017. anpuh.org/resources/anais/54/1502848703_ARQUIVO_CarineNevesAlves_ Coloniaversaofinalemi508.pdf

SOIHET, Rachel (1989). Condição feminina e ordem urbana (1890-1930). RJ: Forense.

VENÂNCIO, Ana Torres (2011). Da colônia agrícola ao hospital-colônia: configurações para a assistência psiquiátrica no Brasil na primeira metade do século XX. História, Ciências, Saúde-Manguinhos, 18(Supl. 1), pp. 35-52. Recuperado em 2 de agosto de 2019, de https://dx.doi.org/10.1590/So104-59702011000500003

Recebido em 25/02/2019.

Aceito em 28/05/2020.

\section{6}

